\title{
Seed Coat Permeability Studies in Wild and Cultivated Species of Soybean
}

\author{
Subhash Chandra*, Raju R. Yadav, Shatakshi Poonia, Yashpal, \\ Darasing R. Rathod, Ashish Kumar, S.K. Lal and A. Talukdar
}

\author{
Division of Genetics, ICAR- Indian Agricultural Research Institute, New Delhi, India \\ *Corresponding author
}

\begin{tabular}{|c|c|}
\hline & A B S T R A $\mathbf{C}$ \\
\hline & \multirow{7}{*}{$\begin{array}{l}\text { Soybean [Glycine } \max \text { (L.) Merr.] Seeds loose viability at a rapid pace under tropical and } \\
\text { subtropical conditions. Poor seed longevity in cultivated soybean genotypes may } \\
\text { associates with seed size, testa colour and seed coat permeability. Present study aims to } \\
\text { understand kinetics of imbibation and evaluate the seed coat permeability in Glycine } \\
\text { tomentella, Glycine soja and Glycine max. Out of all } 125 \text { genotypes of three species, } 20 \\
\text { genotypes of wild annual and perennial species were small and hard seeded. All black } \\
\text { seeded genotypes of three species including cultivated soybean were small in size, } \\
\text { suggesting positive correlation of testa colour with seed size. There was strong positive } \\
\text { correlation between } 100 \text { seed weight and seed coat permeability percentage based on } 6 \\
\text { hours rapid imbibation test (0.83) and Seed coat permeability assessment in germination } \\
\text { paper after } 7 \text { days }(0.81 \text { ). Kinetics of Imbibation suggest that } G \text {. max starts uptake water } \\
\text { after some minutes, but seeds of G.tomentella imbibes water after } 78 \text { hours. Seed weight of } \\
\text { G. soja genotype remained constant even after } 4 \text { days. Genotype of } G \text {. max (DS } 9712 \text { ) } \\
\text { imbibes water up to } 24 \text { hours with steady linear curve, after that it becomes constant up to } \\
\text { germination. Variability in seed coat permeability (44\%) after } 7 \text { days slow imbibation in } \\
\text { G. soja (DC } 2008-1 \text { ) suggests its use in introduction of optimum permeability behavior in } \\
\text { G. max to slow down the extra leaching for improvement in seed longevity. }\end{array}$} \\
\hline & \\
\hline Glycine, & \\
\hline $\begin{array}{l}\text { Imbibation, } \\
\text { Seed coat } \\
\text { permeability, SCP, } \\
\text { Seed longevity. }\end{array}$ & \\
\hline Article Info & \\
\hline $\begin{array}{l}\text { Accepted: } \\
23 \text { June } 2017 \\
\text { Available Online: } \\
10 \text { July } 2017\end{array}$ & \\
\hline & \\
\hline
\end{tabular}

\section{Introduction}

Soybean is a major component in the diet of million people throughout the world. It plays vital role in nutritional security as it is a rich source of protein and oil. Although soybean is grown across the world, yet United States of America, Brazil, Argentina, China and India are the major producers. Taxonomically, the genus Glycine is divided into two subgenera: Glycine (with perennial species) and Soja (with annual species). Subgenus Soja includes the diploid species Glycine max (cultivated soybean) and Glycine soja(wild progenitor). Subgenus Glycine is currently consisting of 30 wild perennial species including Glycine tomentella, Glycine tabacina etc. (Singh et $a l$., 2014). The typical cultivated soybean displays a bush-type growth habit with a stout primary stem and sparse branches, bearing large seeds with variable seed coat colors, whereas the wild type is a procumbent or climbing vine with a slender, many-branched stem bearing small, coarse black seeds.

Soybean seeds are the important regenerative unit which cannot retain their viability indefinitely. Seed coat, the outer covering of every mature seed, is an important part of the 
seed and is associated with preservation of integrity of internal seed parts, protection of embryo against mechanical injuries and regulation of gaseous exchange between embryo and environment. It also offers tolerance to fungal activity, flooding, and protection to microbial attacks. The seed coat is also related to seed viability under delayedharvest field condition, seed longevity under humid environments and inhibition against rapid imbibation of water, which often deteriorates the germination (Kebede et al., 2014). Seeds with impermeable seed coat often results in adverse quality, and cost factors in processing seeds for vegetable oil and soy foods, and they affect the texture and consistency of products such as fermented soy food (Jang et al., 2015).

Soybean seed reaches its maximum potential for germination and vigour at physiological maturity (Crookston et.al., 1978), which then gradually declines till harvest, followed by a more rapid decline thereafter. Loss of germination potential or viability is more acute in tropical and sub-tropical regions compared to temperate environments.

However, hard seed coat (Tiwari et al., 1995), small seed size (Tiwari et al., 1989), black seed coat (Dassou et al., 1984) and tight attachment of the seed coat to the cotyledons (Kuchlan et al., 2010) are useful parameters for viability in tropical environment. Seeds of the wild type soybeans with hard seed coat exhibit better germination under tropical environment than the cultivated type. However, limited information is available on seed coat permeability and pattern of imbibitions in wild and cultivated germplasm of soybean.

Therefore, the current study was conducted to evaluate seed coat permeability in the seeds of cultivated ( $G$ max ) and two wild type soybean species ( $G$ soja and $G$ tomentola) under ambient storage and to see their effect on seed viability.

\section{Materials and Methods}

\section{Plant material}

The experimental material (125 genotypes) consisted of an accession of $G$ tomentella, 19 accession of $G$ soja and 105 genotypes of $G$ max. The cultivated genotypes included high yielding popular cultivars, advanced breeding lines and exotic stocks (Table 1). The seeds, which were obtained from the Division of Genetics, IARI, New Delhi, varied in testa colour, seed size and seed weight.

Seed coat color of all the 125 genotypes was recorded by visual comparison with the 'color chart' of Royal Horticultural Society, London under natural day light. Three replicates of 100 randomly selected seeds were taken for determination of seed weight. The mean value of the 3 replications was expressed in grams. Based on 100-seed weight, the genotypes were categorized as bold (>10 g), medium (8 $10 \mathrm{~g})$ and small $(<8 \mathrm{~g})$ seeded type on basis of size diversity.

For understanding the kinetics of imbibitions, the water uptake pattern was measured as per Hahlis and Smith (1997). Ten seeds of five genotypes viz., G. tomentella, DC 2008-1, PI 424079, DS9712 and JS 335 were soaked in $25 \mathrm{ml}$ of distilled water at room temperature and their weight was recorded at every two hours interval up to $24 \mathrm{~h}$. Three genotypes, DC 2008-1 (G. soja) and DS 9712 (G. max) and $G$. tomentella were used to understanding pattern of imbibation up to 96 hours with interval of 4 hours in another experiment. The rate of water uptake was depicted as percentage increase over the initial weight of the seeds with time. Seed coat permeability (SCP) was tested through Rapid and Slow imbibitions tests. For rapid imbibitions test, 
20 seeds of each genotype in 3 replications were soaked in $100 \mathrm{ml}$ of distilled water for 6 hrs at room temperature. For slow imbibitions test, 50 seeds of each genotype in three replications were placed in water-moistened germination paper towels, which were then rolled up and placed vertically in plastic containers on a shelf in a germinator. The towels were maintained at near $100 \%$ humidity for 7 days. SCP (\%) was recorded as percent of seeds imbibed water in respective tests (Kebede et al., 2014). As per Sun et al., (2015), the genotypes with SCP $<20 \%$ were categorized as hard-seeded and genotypes with SCP > 80\% were grouped as soft-seeded. Data were analyzed for ANOVA, MSD, correlation coefficient using SAS software package version 9.4. All the replicated data were subjected to Tukey's Studentized Range (HSD) Test.

\section{Results and Discussion}

\section{Seed color}

Seeds of all but one G. soja accessions were dull black; PI366120 had shiny black seeds. Seeds of the single $G$. tomentella accessions were also dull black. However, enough variability for color was observed in the seeds of cultivated type i.e. $G$ max. Out of $105 G$ max genotypes, 69 had yellow seeds and 25 had black seeds. Besides, 6, 3 and 2 genotypes had yellow-green, brown and green seeds, respectively. During domestication, people preferred yellow colored seeds over black and hence most of the cultivated genotypes have yellow seeds. However, black colored genotypes like Kalitur are also popular locally.

\section{Seed weight}

Weight of the seeds is an important trait. It influences consumers' preferences and market price, as well. In general, wild type genotype possesses smaller seeds and vice versa. In this study, wide variation was observed among the genotypes for the seed weight. $G$. tomentella accession had the smallest seeds (100-seed wt. $=0.5312 \mathrm{~g}$ ) and the $G$. $\max$ genotype Dsb19 had the largest seeds (100-seed wt. $=13.52 \mathrm{~g}$ ). The 100 -seed weight of the $G$. soja accessions ranged from 0.561g (DC 2008-1) to $2.072 \mathrm{~g}$ (PI 406684) with an average of $1.26 \mathrm{~g}$, while that in G. max ranged from $5.06 \mathrm{~g}$ (UPSL-34) to $13.52 \mathrm{~g}$ (Dsb 19) and had an average weight of $8.43 \mathrm{~g}$ (Table 2). Among the cultivated genotypes, yellow seeded genotypes had highest mean seed weight $(9.27 \mathrm{~g} / 100$ seeds), followed by brown $(8.16 \mathrm{~g} /$ 100 seeds), yellow-green (7.46g/100seeds) and green $(7.01 \mathrm{~g} / 100$ seeds). Accordingly, all the 20 accessions of wild type soybean were categorized as small seeded, while 48, 42 and 20 genotypes of the cultivated type were classified as small, medium and large seeded, respectively.

\section{Dynamics of imbibition}

Imbibition pattern of seeds is primarily governed by permeability of the seed coat (Kuchlan et al., 2010). More permeable the seed coat more is the imbibitions and viceversa. It was observed that the cultivated genotypes viz., DS9712 and JS335 started imbibing quickly after soaking, and there was an increase in fresh weight of the seeds up to 24 hrs. However, no imbibitions were observed in the seeds of G. soja (DC 2008-1 and PI 424079) and G. tomentella accessions (Fig. 1). Therefore, the seeds of the $G$ soja and $G$ tomentella were classified as hardseeded while that of $G$ max was rated as softseeded. Among the soft seeds, the rate of imbibitions was not uniform. It was more in JS335 (0.196 g/h) than DS9712 (0.032 g/h) in the first two hours, which was later reversed.

It was further observed that seeds of $G$ soja accession DC2008-1 did not imbibe even up 
to $96 \mathrm{hrs}$. It indicated that the seed coat of this accession is highly impermeable. Similarly, $G$. tomentella seeds started imbibing only after $78 \mathrm{hrs}$, of course at a very slow rate. On the other hand, seeds of DS9712 ( $G$ max $)$ started imbibing minutes after soaking. There was a linear increase in rate of imbibitions up to $24 \mathrm{hrs}$ after which it remained stagnant up to $72 \mathrm{hrs}$ beyond which weight gain was observed due to germination.

Table.1 Genotypes used in experiment for testing seed coat permeability

\begin{tabular}{|c|c|c|c|c|c|c|c|}
\hline S.No. & Genotype & S.No. & Genotype & S.No. & Genotype & S.No. & Genotype \\
\hline 1 & G. tomentella & 33 & UPSL-117-B & 65 & PS-1477 & 97 & JAVA-16 \\
\hline 2 & PI-464925-B & 34 & USSL-291 & 66 & PS-1480 & 98 & $\mathrm{~J}-231$ \\
\hline 3 & PI-464925-A & 35 & EC-456615 & 67 & MACS-1336 & 99 & JS-76-257 \\
\hline 4 & PI-561355 & 36 & EC-457442 & 68 & SL-900 & 100 & M253 \\
\hline 5 & PI-464869-A & 37 & EC-457472 & 69 & DSB-19 & 101 & MACS565 \\
\hline 6 & PI-522183-B & 38 & EC-471635 & 70 & PS-1503 & 102 & MAUS-2 \\
\hline 7 & PI-464889-A & 39 & EC-457189 & 71 & DSB-21 & 103 & NRC-21 \\
\hline 8 & PI-407294 & 40 & DS-9909 & 72 & PS-1505 & 104 & PK-1225A \\
\hline 9 & PI-407292 & 41 & MAUS-164 & 73 & NRC-89 & 105 & UPSL-19 \\
\hline 10 & PI-406684 & 42 & PK-1347 & 74 & AMS-56 & 106 & UPSL-29 \\
\hline 11 & PI-366120 & 43 & TS-148-22 & 75 & DS-2708 & 107 & UPSL-34 \\
\hline 12 & PI-507805 & 44 & MACS-869 & 76 & PS-1518 & 108 & UPSL-736 \\
\hline 13 & PI-423991 & 45 & DS-22005 & 77 & DS 61 & 109 & EC-458342 \\
\hline 14 & PI-522229 & 46 & DS-9817 & 78 & DS 178 & 110 & EC 1023 \\
\hline 15 & PI-507830-B & 47 & DS-9819 & 79 & DS 76-37-2 & 111 & DS MM 64 \\
\hline 16 & PI-326582-B & 48 & His-01 & 80 & DS 93-3 & 112 & G 2603 \\
\hline 17 & PI-424051 B & 49 & JS-94-67 & 81 & EC13969 & 113 & G 2253 \\
\hline 18 & PI-424079 & 50 & KB-222 & 82 & EC343361A & 114 & G 2601 \\
\hline 19 & PI-424032 & 51 & MACS-450 & 83 & EC1021 & 115 & MACS 694 \\
\hline 20 & DC-2008-1 & 52 & PK-1024 & 84 & EC36961 & 116 & EC 471919 \\
\hline 21 & DS 9712 & 53 & PK-1041 & 85 & EC39873 & 117 & EC 472134 \\
\hline 22 & DS-76-1-2-1 & 54 & VLS-61 & 86 & EC97351 & 118 & G 395 \\
\hline 23 & G-2215 & 55 & SL-679 & 87 & EC105790 & 119 & UPSL 163 \\
\hline 24 & G-2132 & 56 & SL-710 & 88 & G2265 & 120 & UPSL 332 \\
\hline 25 & G-2144 & 57 & E-20 & 89 & G2344 & 121 & DS 74 \\
\hline 26 & PK-1243 & 58 & SL688 & 90 & G2608 & 122 & AMSS 34 \\
\hline 27 & PK-1135 & 59 & PKS-34 & 91 & JS 335 & 123 & NRC 7 \\
\hline 28 & Bragg & 60 & NRC-71 & 92 & G2651 & 124 & PK 416 \\
\hline 29 & TGX1855-530 & 61 & NRC-78 & 93 & G3023 & 125 & PK 472 \\
\hline 30 & TGX1864-15F & 62 & DS-2614 & 94 & GUJ-SOY-1 & & \\
\hline 31 & TAMS-38 & 63 & JS-20-05 & 95 & IC-144409 & & \\
\hline 32 & UGM-34 & 64 & DSb-15 & 96 & IC-141446 & & \\
\hline
\end{tabular}

(S.No. 1: G. tomentella; 2 to 20: G. soja; 21 to 125: G. max)

Table.2 Descriptive statistics for 100 seed weight and

Seed coat permeability among the three species of soybean

\begin{tabular}{lllllll}
\hline Species & \multicolumn{2}{c}{ 100 seed Weight } & \multicolumn{3}{c}{ SCP\% (7 days basis) } \\
\cline { 2 - 7 } & Range & Mean & SD & Range & Mean & SD \\
\hline G. max & $5.06-13.52$ & 8.48 & 1.91 & $92.0-100$ & 99.69 & 0.971 \\
G. soja & $0.56-2.07$ & 1.26 & 0.42 & $3.1-44.0$ & 3.37 & 10.5 \\
G. tomentella & 0.53 & 0.53 & - & 66.0 & 66.0 & - \\
\hline
\end{tabular}


Fig.1 Pattern of water imbibation in wild and cultivated soybean

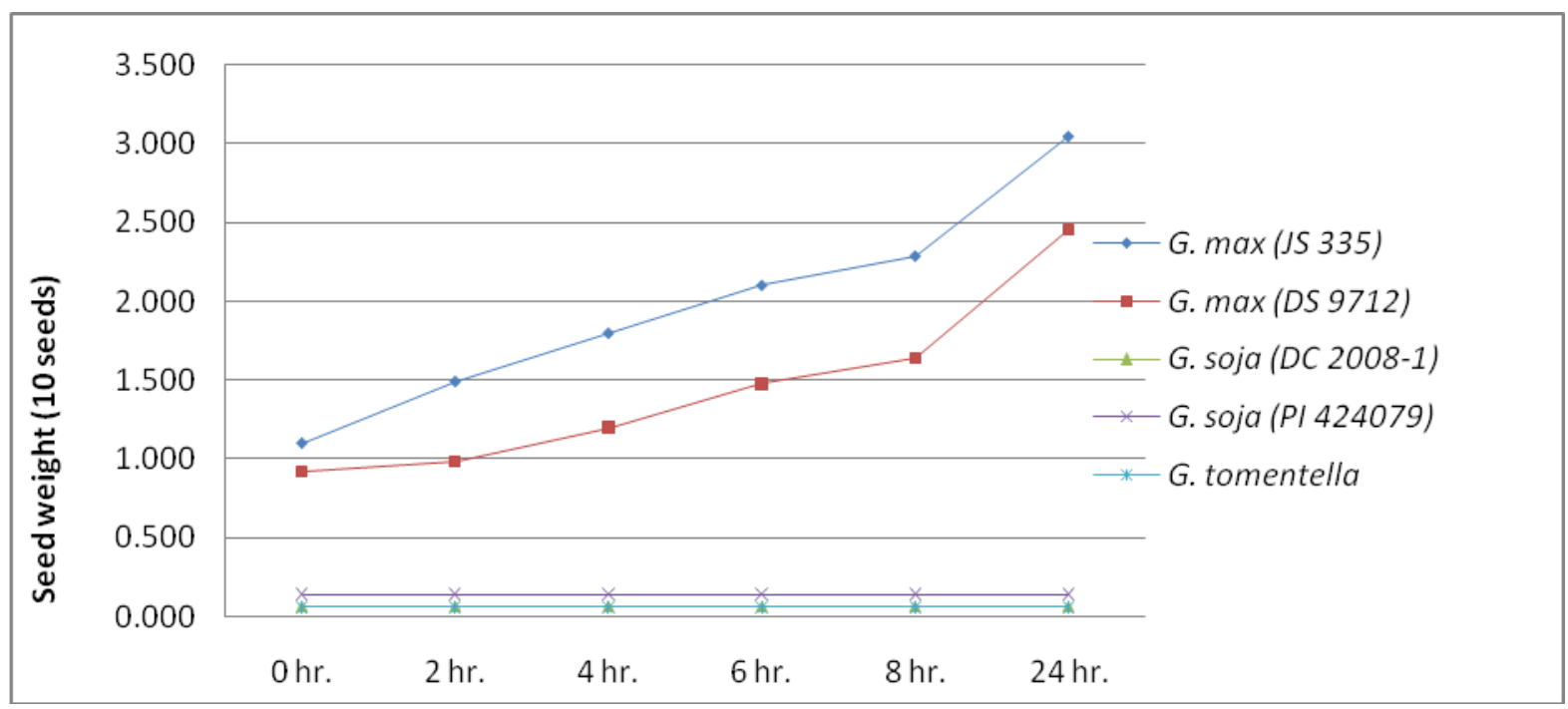

\section{Seed coat permeability}

Rapid permeability test: Permeability of the seed coat of all the 125 genotypes was checked after 6 hrs of soaking (rapid imbibitions) and 7 days of soaking (slow imbibitions). Those genotypes whose $<20 \%$ seeds imbibed within $6 \mathrm{hrs}$ were classified as hard seeded. Similarly, genotypes whose $>80 \%$ seeds imbibed within $6 \mathrm{hrs}$ were classified as soft-seeded. Accordingly, all the accessions of $G$. soja and $G$. tomentella were rated as hard-seeded as it did not imbibe any water $(\mathrm{SCP}=0 \%)$ within 6 hrs. Similarly, 81 genotypes of G. max out of 105 had $90-100 \%$ SCP and were classified as soft-seeded.

Slow permeability test: Slow imbibitions test indicated $66 \%$ permeability in seeds of G. tomentella. Similarly, 14 out of 19 G. soja genotypes showed $0 \%$ permeability in the slow imbibitions test. G. soja accession DC2008-1 had 44\% SCP and PI507830B, PI366120, PI464889A and PI424032 had 3\%, $4 \%, 5 \%$ and $6 \%$ permeability, respectively. Therefore, all the accessions of G. soja were rated as hard-seeded. Genotypes of the cultivated soybean found to have soft seeds as all the genotypes had SCP ranging from 92-
$100 \%$. Mean value of SCP \% in the slow permeability test were recorded as $3.37 \%$, $66 \%$ and $99.69 \%$ in G. soja, G. tomentella and G. max, respectively.

A very strong correlation (0.98) was observed between the result of SCP under rapid and slow permeability test. It indicated that rapid permeability test i.e. imbibitions of 6 hours can be effectively used for testing permeability of seeds. It will save time and energy. Similarly, seed weight found to have strong correlation with the seed coat permeability. So, large seeds would have high seed coat permeability.

The morphological and physiological changes associated with domestication can be delimitated into adaptation syndromes resulting from natural or deliberate human selection (Harlan et al., 1992). Hard seed is an adaptive trait which ascertained in wild relatives of soybean and maintained longer viability in them. In the present study, all the accessions of G. soja except DC 2008-1 had permeability less than $7 \%$. The seeds of DC2008-1 are highly viable (data not shown). Therefore, transferring partial permeable trait of DC 2008-1 to cultivated type might 
increase seed viability in soybean. Seed size found to have strong correlation with seed coat color and viability. Black genotypes of all the species including G.max had small seeds $(<8 \mathrm{~g})$ and in general were highly viable. Seed coat permeability was strongly associated with process of domestication (Liu et al., 2007). All genotypes of domesticated soybean are soft seeded. However, soft seeded genotypes are having short viability. Therefore, breeding efforts need to be oriented to increase viability of soybean seeds without compromising seed coat permeability. The information generated in this study would pave the way for developing soybean genotype with high viability and permeability.

\section{Acknowledgement}

The first author is thankful to the UGC and ICAR-IARI, New Delhi, India for the grant of Junior Research Fellowship and facilities during Ph.D. programme.

\section{References}

Crookston R. K. and Hill D. S. 1978 A visual indicator of the physiological maturity of soybean seed. Crop Sci., 18: 867-870

Dassou S \& Kueneman E. A. 1984 Screening methodology for resistance to field weathering in soybean seed Crop Sci 24: $774-778$

Hahalis, D.A. And Smith M.L. 1997 In Basic and Applied Aspects of Seed Bio. (Eds., R.H. Ellis, M. Black, A.J. Murdoch and T.D. Hang) pp 507-514. Kulwar. Acad. Publ. Boston

Harlan JR. 1992. Crops and man, 2nd edn.
Madison, WI: American Society of Agronomy, Inc. and Crop Science Society of America, Inc

Jang S.J., Sato M., Sato K., Jitsuyama Y. Fujino K. and Mori H, et al., 2015 A Single-Nucleotide Polymorphism in an Endo-1,4- $\beta$-Glucanase Gene Controls Seed Coat Permeability in Soybean. PLOS ONE 10: (6)

Kebede H, Smith J.R. and Ray J.D. 2014 Identification of a single gene for seed coat impermeability in soybean PI 594619 Theor. App. Genet. 127: 19912003

Kuchlan M K, Dadlani M \& Samuel D V K 2010 Seed coat properties and longevity of soybean seeds Journal of New Seeds 11: 239-249

Liu, B., Fujita,T., Yan, Z.H., Sakamoto, S., $\mathrm{Xu}$, D. and Abe, J. (2007). QTL mapping of domestication related traits in soybean (Glycine max). Ann. of Bot. 100: 1027-1038.

Singh R.J. and Nelson R.L.2014 Methodology for creating alloplasmic soybean lines by using Glycine tomentella as a maternal parent Plant Breeding 133 624-631

Sun L., Miao Z., Cai C. and Zhang D et al., $2015 \mathrm{GmHs}$-1, encoding a calcineurinlike protein, controls hard-seededness in soybean Nature Genetics 47:939-943

Tiwari S P \& Bhatia V S 1995 Association of seed anatomical characters with seed longevity in soybean Seed Res 23: 3839

Tiwari S P \& Joshi H J 1989 Correlation and path analysis for seed quality characters in soybean Oil Seed Res 16: 51-57

\section{How to cite this article:}

Subhash Chandra, Raju R. Yadav, Shatakshi Poonia, Yashpal, Darasing R. Rathod, Ashish Kumar, S.K. Lal and Talukdar, A. 2017. Seed Coat Permeability Studies in Wild and Cultivated Species of Soybean. Int.J.Curr.Microbiol.App.Sci. 6(7): 2358-2363. doi: https://doi.org/10.20546/ijcmas.2017.607.279 